\title{
Narrative review of congenital lung lesions
}

\author{
Shaun M. Kunisaki \\ Division of General Pediatric Surgery, Johns Hopkins Children's Center, Johns Hopkins University School of Medicine, Baltimore, MD, USA \\ Correspondence to: Shaun M. Kunisaki, MD, MSc. Robert and Jane Meyerhoff Endowed Professor, Johns Hopkins Children's Center, Johns Hopkins \\ University School of Medicine, 1800 Orleans Street, Suite 7353, Baltimore, MD 21287 USA. Email: skunisa1@jhmi.edu.
}

\begin{abstract}
This article reviews the contemporary diagnosis and management of antenatally diagnosed congenital lung lesions. These anomalies, which include congenital pulmonary airway malformation (CPAM) (formerly congenital cystic adenomatoid malformation), bronchopulmonary sequestration (BPS), bronchogenic cyst, and congenital lobar emphysema (CLE), are relatively rare but are increasingly encountered by clinicians because of the improved resolution and enhanced sensitivity of fetal ultrasound. Serial assessment of these lesions throughout pregnancy remains the norm rather than the exception. Perinatal management strategies may differ based on initial size and growth patterns of these masses until delivery. Fetal magnetic resonance imaging and other diagnostic testing can sometimes be helpful in providing additional prognostic information. Over the last decade, maternal steroids have become standard of care in the management of larger lesions at risk for nonimmune hydrops. As a result, fetal surgical procedures, including open resection, thoracoamniotic shunting, and ex utero intrapartum treatment (EXIT), are less uncommonly performed. Decisions regarding whether delivery of these fetuses should occur in a tertiary care center with pediatric surgery coverage versus delivery at a local community hospital are now highly relevant in most prenatal counseling discussions with families. Large lung malformations may require urgent surgical removal in the early postnatal period because of respiratory distress. Other complications, such as recurrent pneumonia, pneumothorax, and cancer, are indications for postnatal lung resection on an elective basis. Many children are good candidates for minimally invasive (thoracoscopic) surgical approaches as an alternative to resection by thoracotomy. In the vast majority of cases, the overall prognosis remains excellent.
\end{abstract}

Keywords: Congenital lung lesion; congenital pulmonary airway malformations (CPAM); bronchopulmonary sequestrations (BPS); fetal surgery

Submitted Apr 29, 2020. Accepted for publication Dec 30, 2020.

doi: $10.21037 /$ tp-20-133

View this article at: http://dx.doi.org/10.21037/tp-20-133

\section{Introduction}

Congenital lung lesions represent a group of anomalies that include congenital pulmonary airway malformations (CPAM), bronchopulmonary sequestrations (BPS), congenital lobar emphysema (CLE) (Figure 1), and bronchogenic cysts (1). Their incidence has increased in recent years based on several population-based studies, which suggest a frequency of 1 in 2,500 live births $(2,3)$. This rising incidence is likely due to the widespread availability of prenatal ultrasound combined with the improved resolution of ultrasound technology that enables the detection of smaller lung lesions.

Fetal pulmonary masses appear to be sporadic without any association with maternal factors such as ethnicity, parity, age, or other factors. A $10-20 \%$ anomaly rate has often been cited (4), but only $5-10 \%$ of fetuses will have another major anomaly coincident with the pulmonary lesion (5). Lung malformations are not associated with karyotype anomalies.

We present the following article on the contemporary 


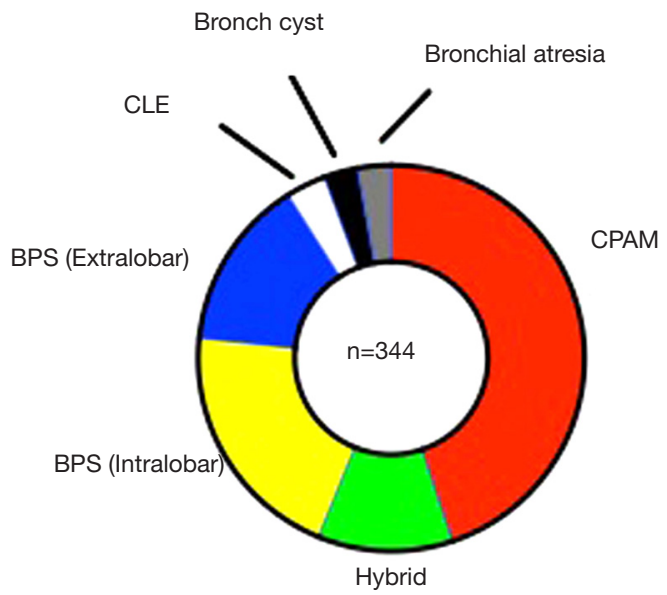

Figure 1 Graph showing the relative frequency of different types of prenatally diagnosed congenital lung lesions, with permission (1).

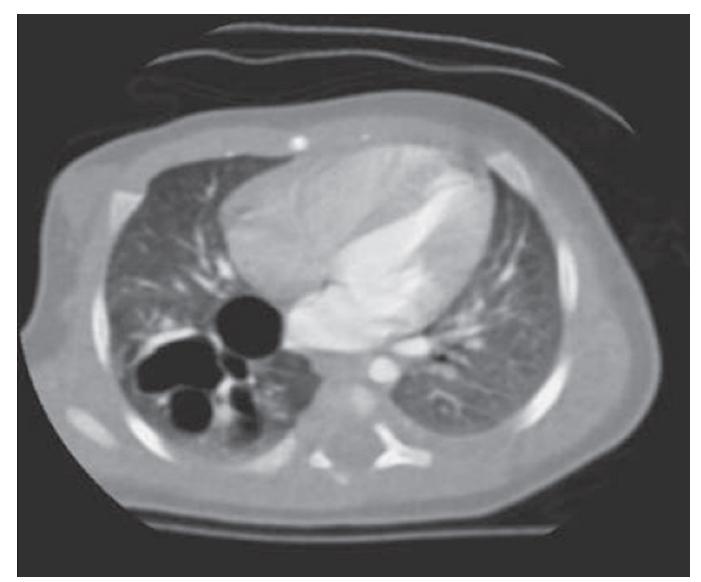

Figure 2 Chest CT transverse section (lung window) showing a congenital pulmonary airway malformation involving the right lower lobe, with permission (6).

diagnosis and management of antenatally diagnosed congenital lung lesions in accordance with the Narrative Review reporting checklist (available at http://dx.doi. org/10.21037/tp-20-133).

\section{Types of lung malformations}

\section{CPAM}

The most frequently encountered lung lesions are CPAMs, which were previously referred to as Congenital Cystic Adenomatoid Malformations or CCAMs (Figure 2) (6).
Historically, CPAMs were classified by the Stocker classification, defined by Roman numerals-type I were macrocystic, type II were mixed, and type III were solid/ microcystic (4). The motivation to adopt the more generic term for these lesions, CPAM, was driven by pathologists who sought more accurate terminology for these lesions, many of which were neither cystic nor adenomatoid. There are five different types of CPAMs, defined by Arabic numerals (0-4) based on the relationship to abnormal histology relative to the main airways (7). Stocker's pathological classification has been widely used to describe prenatal lung lesions, but this practice correlates poorly with postnatal diagnosis and has no real prognostic value. The most useful classification scheme for fetal CPAMs was proposed by Adzick and is simply based on whether they are macrocystic or microcystic by ultrasound (8).

The unifying feature of all lung lesions, regardless of their specific subtype, is aberrant lung morphogenesis during the pseudoglandular stage of fetal pulmonary development. Early fetal proximal airway obstruction may be an inciting event in their pathogenesis $(9,10)$. Further support for this developmental aberration is based on persistent epithelial expression of nuclear regulatory protein, TTF-1 (11). Genetic examination has largely been focused on the basis of faulty branching and budding of the lung. For example, investigators have examined resected CPAMs and found that those masses with the HOXB5 gene present had twice as much cell proliferation and evidence of increases apoptosis when compared to a normal lung (12).

Hamartomas and terminal bronchiole overgrowth are common features on CPAMs on histologic evaluation. Unlike bronchogenic cysts and BPS lesions, most CPAMs are in direct communication with adjacent lung parenchyma. Since CPAMs usually have abnormal alveoli, gas exchange is poor, and larger lesions can expand, causing mass effect to adjacent normal lung tissue. In three-fourths of cases, affects one of the lower lobes (1). Bilateral and multi-lobar disease is uncommon.

Although blood flow within CPAMs is based on the pulmonary vasculature (i.e., pulmonary arteries and veins), mixed/hybrid lesions, which have features of intralobar BPS, are often encountered. These hybrid masses will often have pulmonary venous drainage but will rely on systemic blood supply from the aorta. The high frequency of mixed/hybrid lesions suggests a common disease pathogenesis among the various lung lesions during development (10). 


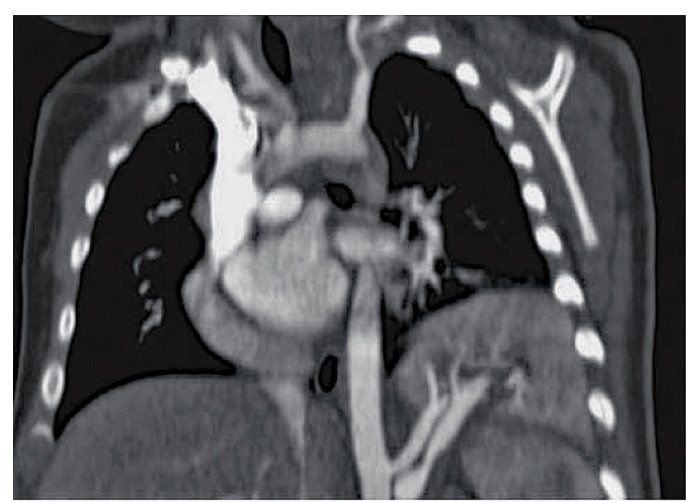

Figure 3 Chest CT coronal section (abdominal window) demonstrating a left bronchopulmonary sequestration with a large systemic blood supply arising from the aorta, with permission (6).

\section{BPS}

BPS are the second most common pulmonary lesion. CPAM and BPS are often confused with one another since they both produce mass effect on adjacent mediastinal structures and have a propensity for the lower lobes. One study has suggested that one-quarter of pulmonary specimens has histology consistent with a CPAM but also is supplied by a systemic arterial blood supply (i.e., hybrid/mixed lesions) (13). Another major and distinct feature of all BPS lesion is the lack of airway communication (sequestration) to the native lung. Accordingly, the abnormal lung tissue tends to be non-aerated although some collateral ventilation via the pores of Kohn from adjacent lung tissue is possible.

As shown in Figure 3, the identification of a systemic arterial blood supply, usually from the thoracoabdominal aorta, is pathognomonic for BPS (14). Less commonly, the systemic artery can arise from the gastric or splenic artery. Over time, large systemic arteries feeding untreated BPS lesions can cause cardiac overload and heart failure. The growth characteristics and management of fetal BPS lesions are similar to those with fetal CPAM (15).

The type major types of BPS are intralobar $(75 \%)$ and extralobar (25\%) (1). Intralobar sequestrations are at increased risk for bacterial seeding with subsequent pneumonia because they are contained within a common visceral pleura with normal aerated lung. Extralobar BPS is much less prone to infectious complications since they represent accessory lobes that have their own distinct pleura and systemic venous drainage that is separate from normal lung tissue.

\section{Bronchogenic cysts}

Bronchogenic cysts are unilocular intrathoracic masses and are much less common than other lung masses. They are foregut malformations that are thought to originate embryologically from anomalous budding of the tracheobronchial tree with subsequent failure to recanalize (16). Based on imaging studies, bronchogenic cysts tend to be more centrally located within the chest. Common locations include paratracheal or adjacent one of the mainstem bronchi. Large, expanding bronchogenic cysts can cause central airways obstruction with or without distal lung hyperinflation. Histologically, bronchogenic cysts contain cartilaginous tissue with ciliated mucus-secreting columnar epithelium. Mucus buildup with the cyst itself can lead to steady enlargement and/or infection.

\section{CLE}

CLE is a rare but well-known disorder associated with acute respiratory distress in newborns. In contrast to CPAM and BPS, antenatal diagnosis is rare (17) due to their isoechoic appearance and lack of mediastinal shift in utero. The CLE is prone to overinflation of the affected parenchyma for a variety of reasons, which can include intrinsic bronchial stenosis, bronchomalacia, extrinsic bronchial narrowing, and polyalveolar lobe (18). Pathologic exam can reveal mild bronchial ectasia consistent with lesions within the bronchial atresia spectrum. As in CPAMs, temporary bronchial stenosis/obstruction in utero is thought to be an important driver of aberrant lung development (10).

Children with CLE often develop progressive air trapping with the affected lung, thereby resulting in shifting of the mediastinal structures to the contralateral thorax and profound respiratory embarrassment (2) (Figure 4). The left upper lobe, often with sparing of the lingual, as well as right middle lobe are most common locations for CLE. CLE isolated to segmental portions of a lobe has been described and may produce minimal symptoms (19). The role of elective resection of asymptomatic CLE is controversial.

\section{Fetal diagnosis}

Approximately $70 \%$ of all congenital lung malformations are now detected during fetal anatomic survey (Figure 5) (20). While ultrasound is a useful tool for the detection of 


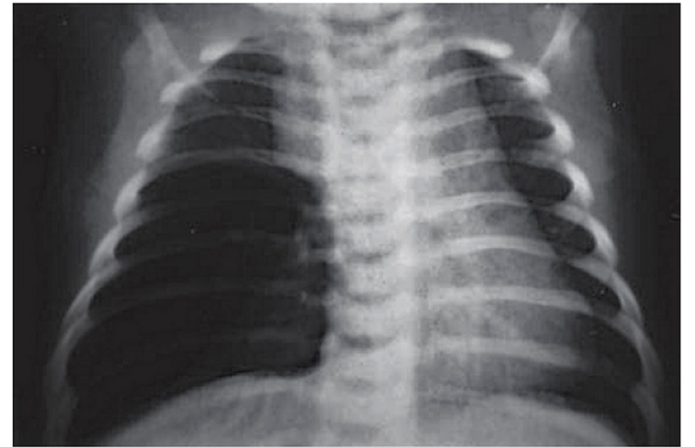

Figure 4 Plain radiograph of the chest (anteroposterior view) in a neonate showing hyperinflation of the right middle lobe with mass effect and mediastinal shift. The lesion was a congenital lobar emphysema, with permission (6).

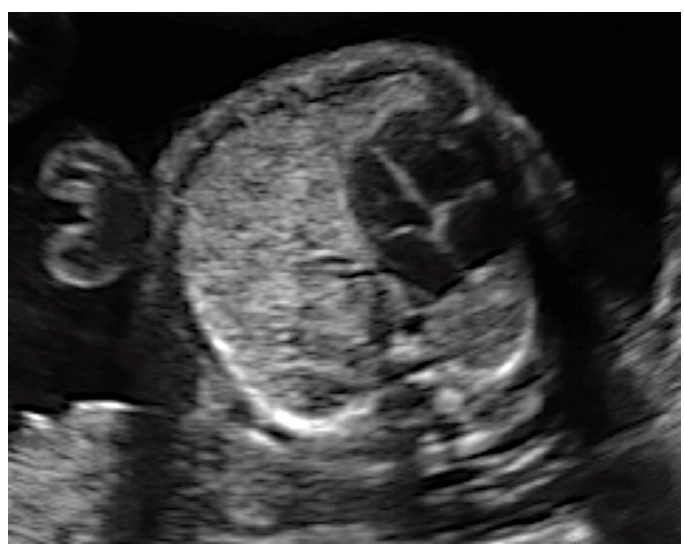

Figure 5 Plain radiograph of the chest (anteroposterior view) in a neonate showing hyperinflation of the right middle lobe with mass effect and mediastinal shift. The lesion was a congenital lobar emphysema, with permission (6).

hyperechoic and cystic lung lesions, there is definite potential to misdiagnose primary fetal lung masses for other anomalies. Congenital diaphragmatic hernia $(\mathrm{CDH})$ is one of the more common errors in fetal diagnosis. CDH carries a much more guarded prognosis but can easily mimic a macrocystic CPAM isolated to the left lower lobe. Other disorders in the differential diagnosis to consider when identifying a suspected lung malformation are shown in Table 1 (21).

The role for amniocentesis remains undefined in the management of fetal lung lesions. Since these are not known to be intimately related to genetic disorders, an amniocentesis is considered unnecessary when a solitary lung lesion is identified. However, if a concomitant anomaly is discovered, complete genetic screening should be performed per obstetrical indications.

The overall perinatal prognosis of a fetus affected by the lung malformation is strongly associated with its overall growth during pregnancy rather than by its underlying histology (5). This concept has been supported in numerous studies, all which have shown that mass size, as opposed to type of lesion, is most predictive of perinatal outcome based on a variety of outcome measures, including fetal hydrops, neonatal respiratory symptoms, and likelihood of lung resection in the newborn period $(5,20,22,23)$. The most common metric for lesion size is the CPAM volume ratio (CVR), which measures the three-dimensional size of the lesion relative to the fetal head circumference (24). The CVR formula is:

$$
\frac{\text { width } \times \text { depth } \times \text { length } \times 0.52}{\text { head circumference }}=C V R
$$

CVR measurements are relatively easy to measure, reproducible, and can be calculated based on transverse and sagittal views on $2 \mathrm{D}$ ultrasound. CVRs are helpful since they are adjusted for fetal size and therefore can be used to track relative growth of the lung lesion over time. Although many maternal-fetal medicine providers have historically focused on secondary parameters, such as polyhydramnios or mediastinal shift, more recent multicenter data suggests that the maximum CVR during gestation is the best predictor of perinatal outcome (20). In the majority of children with small lung lesions, prenatal MRI usually adds little additional diagnostic information that would change management and is therefore probably not costeffective (25). The role of fetal echocardiography remains controversial and should be considered on a case-by-case basis given the low incidence of a concomitant cardiac anomalies (5).

Many lung malformations undergo an initial growth phase between 20 and 26 weeks gestation. This is often followed by plateau or regression phase for the remainder of pregnancy $(15,26)$. However, some lesions do not follow this growth pattern so there remains no widely accepted prediction tool that has been adopted to predict which lesions will change dramatically in size. In some cases, lung lesions may actually completely disappear spontaneously (so-called "vanishing" lesions) although this is usually an artifact since lung malformations often become 
Table 1 Differential diagnosis of fetal congenital lung lesions, with permission (21)

\begin{tabular}{|c|c|}
\hline Disorder & Common ultrasound features \\
\hline Pulmonary agenesis & $\begin{array}{l}\text { Oligohydramnios } \pm \text { fetal anomalies known to be associated with lung agenesis. Associated with Potter's } \\
\text { syndrome and fetal renal anomalies and Preterm premature rupture of membranes }\end{array}$ \\
\hline Pericardial tumors & $\begin{array}{l}\text { Usually heterogenous echogenicity. Fetal pericardial effusion may be present. If cardiac compression is present } \\
\text { other heart failure signs may be present e.g., hydrops fetalis }\end{array}$ \\
\hline $\begin{array}{l}\text { Esophageal duplication } \\
\text { cysts }\end{array}$ & $\begin{array}{l}\text { Cyst identified in fetal midline anywhere from neck to abdomen. Does not communicate with lungs or } \\
\text { esophagus }\end{array}$ \\
\hline Teratoma & $\begin{array}{l}\text { Most common site is the anterior mediastinum. } 90 \% \text { cystic and can be multiloculated. Fat and fluid levels seen } \\
\text { in the cysts with occasional calcification }\end{array}$ \\
\hline $\begin{array}{l}\text { Congenital high airway } \\
\text { obstruction syndrome } \\
\text { (CHAOS) }\end{array}$ & $\begin{array}{l}\text { Bilateral lungs distended with fluid. There can be cardiac compression, leading to early hydrops and fetal heart } \\
\text { failure }\end{array}$ \\
\hline Thymic masses & $\begin{array}{l}\text { Cystic structure within the anterior mediastinum that can cause mediastinal shift. Can be unilocular or } \\
\text { multilocular }\end{array}$ \\
\hline
\end{tabular}

sonographically isogenic with normal lung parenchyma by term $(27,28)$. In about $40 \%$ of cases, the lesion can be detected by postnatal chest CT scan (28). Therefore, in all lung malformations that are not detectable towards the end of pregnancy, parents should be informed that late gestation fetal ultrasound and postnatal plain films cannot be used to rule out the presence of a previously diagnosed prenatal lung lesion since the mass often still present when imaged by postnatal CT.

A proposed CVR-based algorithm based on recent data from the Midwest Pediatric Surgery Consortium is shown in Figure 6 (20). Peak CVRs less than 0.9-1.0 throughout the pregnancy are highly predictive $(>90 \%)$ of asymptomatic disease at birth (Figure 7) (5). In cases where the lung malformation is small, prenatal consultation with a pediatric surgeon is helpful for most families and can help establish a relationship with the parents for follow up after birth. Those with small lung lesions can be safely delivered at a local birthing center without substantial neonatal intensive care or pediatric surgical support. A normal vaginal delivery can be performed if a cesarean is not indicated for other clinical reasons.

For larger prenatal lesions, such as those with CVRs greater than 1.0 in association with mass effect, hypoplasia of the adjacent fetal lung can occur (29). Massive lesions can also cause mediastinal compression, leading to esophageal obstruction and polyhydramnios. The most feared complication associated with massive lung masses is nonimmune hydrops, which can present with ascites, pleural/pericardial effusions, skin edema, and/ or placentomegaly. Mass effect on the heart can lead to compromised venous return to the right atrium and ultimately in utero heart failure (30,31). Fortunately, hydrops probably occurs in fewer than $10 \%$ of cases based on a multi-institutional report (1). Fetuses at increased hydrops risk are those with an initial CVR of at least $1.4(20,24)$. Although many fetuses with high CVRs will not develop hydrops, this group remains clearly at increased risk for respiratory symptoms and may require ventilator support in the neonatal intensive care unit, emergency lung resection, and less commonly, extracorporeal membrane oxygenation (ECMO).

\section{Fetal management}

Maternal steroids, thoracoamniotic shunts, fetal mass resection, and ex utero intrapartum treatment (EXIT) procedures may play an important therapeutic role in large congenital lung lesions with hydrops or impending hydrops. 
CVR-based guidelines for the management of fetal lung malformations

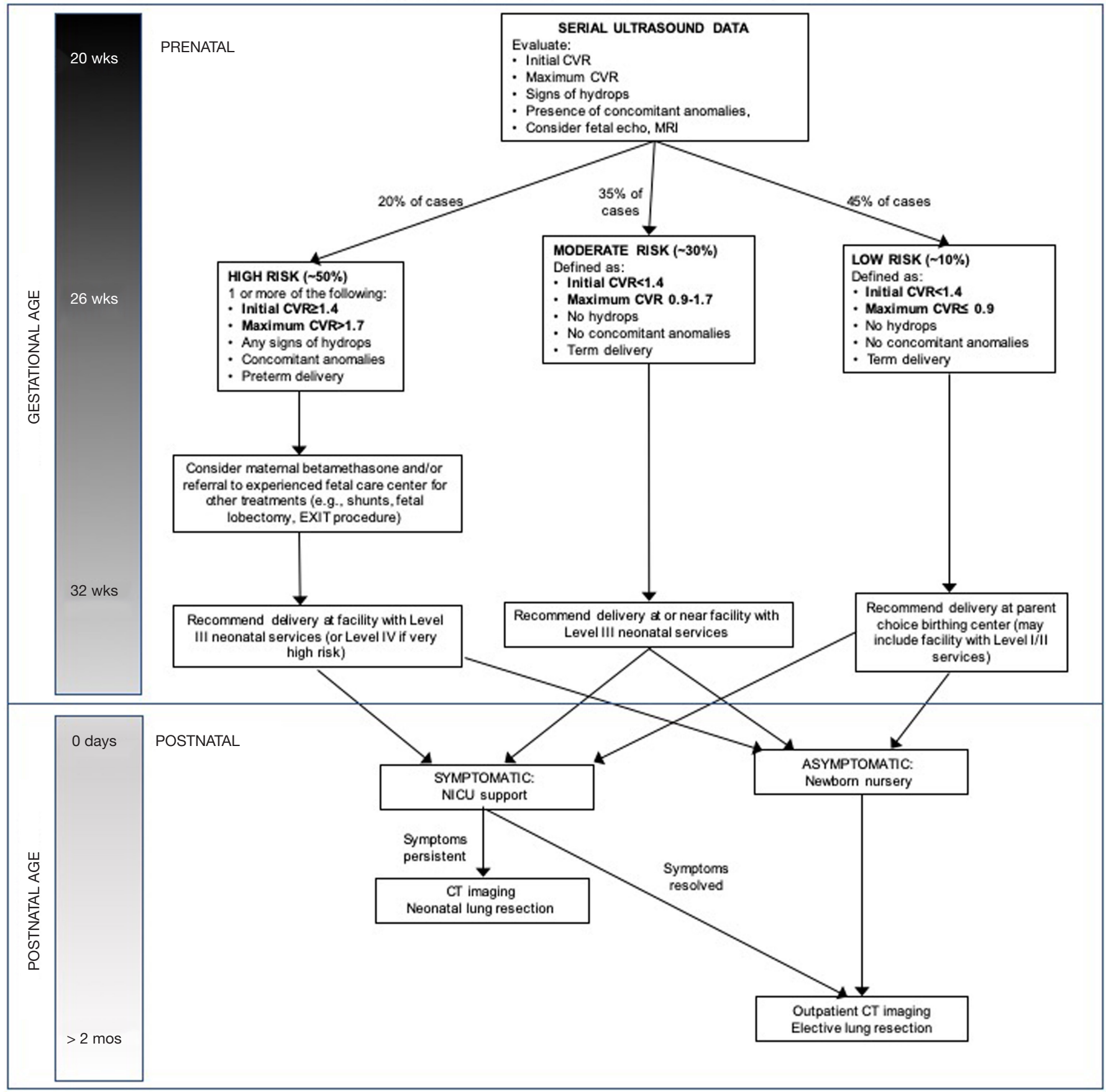

Figure 6 Congenital pulmonary airway malformation volume ratio (CVR)-based management algorithm for prenatally diagnosed lung lesions, with permission (20). 

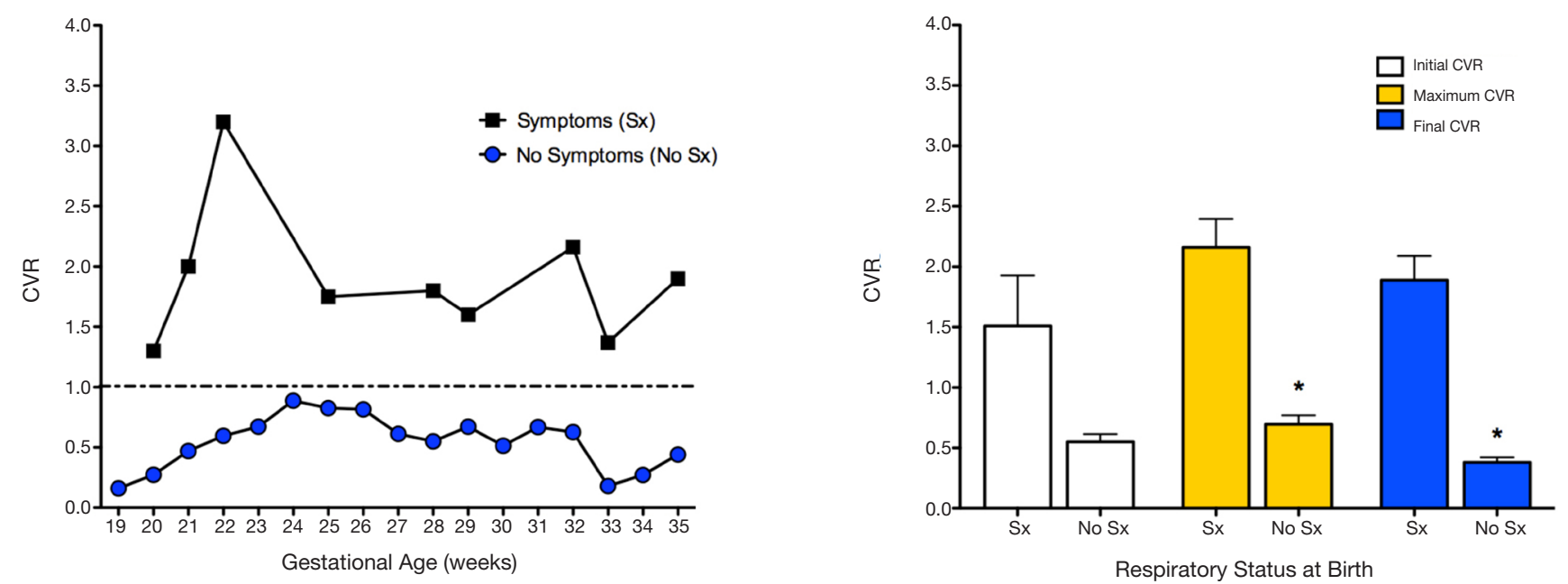

Figure 7 Correlation between the congenital pulmonary airway malformation volume ratio (CVR) and neonatal respiratory symptoms (Sx). Line graph of CVR stratified based on presence or absence of respiratory symptoms (left) and vertical bar graph of CVR based on initial, maximum, and final CVR measurements (right), with permission (5). ${ }^{*} \mathrm{P}<0.05$.

\section{Maternal steroids}

The beneficial effect of steroids in the management of hydropic fetal lung lesions was a serendipitous discovery first reported by the University of California, San Francisco (UCSF) group in 2003 (32). In this case series, they described three fetuses with lung lesions and non-immune hydrops who either declined or were not candidates for fetal surgery. In an attempt to improve fetal lung maturity before birth, maternal betamethasone was given with the unexpected observance of complete hydrops resolution and near-term delivery without any respiratory compromise. Since this initial experience, subsequent studies at other major American fetal centers have shown a similar positive response using maternal steroids, particularly in microcystic lesions before 26 weeks gestation. In a retrospective review of patients with microcystic CPAMs and hydrops, $92 \%$ (12 of 13) fetuses in the steroid-treated group survived to delivery compared to $82 \%$ (9 of 11) in the open fetal surgery group (33). Moreover, only $56 \%$ of the open fetal surgery group survived to discharge whereas $83 \%$ of the steroid group survived to discharge. In another study, maternal steroids were associated with a decline in the CVR and resolution of hydrops in $80 \%$ of cases (34).

Given these results and the relatively low maternal-fetal risk profile associated with two doses of systemic steroids, maternal betamethasone $(12.5 \mathrm{mg} /$ day intramuscular $\times 2$ days) is now considered first-line therapy for large microcystic lesions (e.g., CVR >1.6) with hydrops or impending hydrops. Based on a recent multi-center study of surgical patients, antenatal material steroids were administered to $12 \%$ of fetal lung lesions (20). Since the positive effect of steroids has been rather compelling, a randomized control trial of maternal steroids would currently not be considered ethical because it would withhold treatment in the control arm of mothers carrying hydropic fetuses.

However, it is important to note that steroids have never been rigorously tested compared to observation alone, and that the drug appears to be most effective in fetuses less than 26 weeks gestation with microcystic disease. We have seen a precipitous decline in the need to perform open fetal surgery for hydropic fetuses since the adoption of steroids. The Cincinnati group, among others, has shown that steroids do not seem to be as effective in hydropic fetuses with macrocystic lesions, implying a different underlying developmental biology (35). We can only speculate on the mechanism of action for the therapeutic effect of steroids, but current thinking is that steroids may facilitate the transition from the canalicular to saccular stage of development, in part by inhibiting abnormal mesenchymal proliferation within the lung lesion.

\section{Thoracoamniotic shunts}

There is a clear role for catheter-based interventions, 


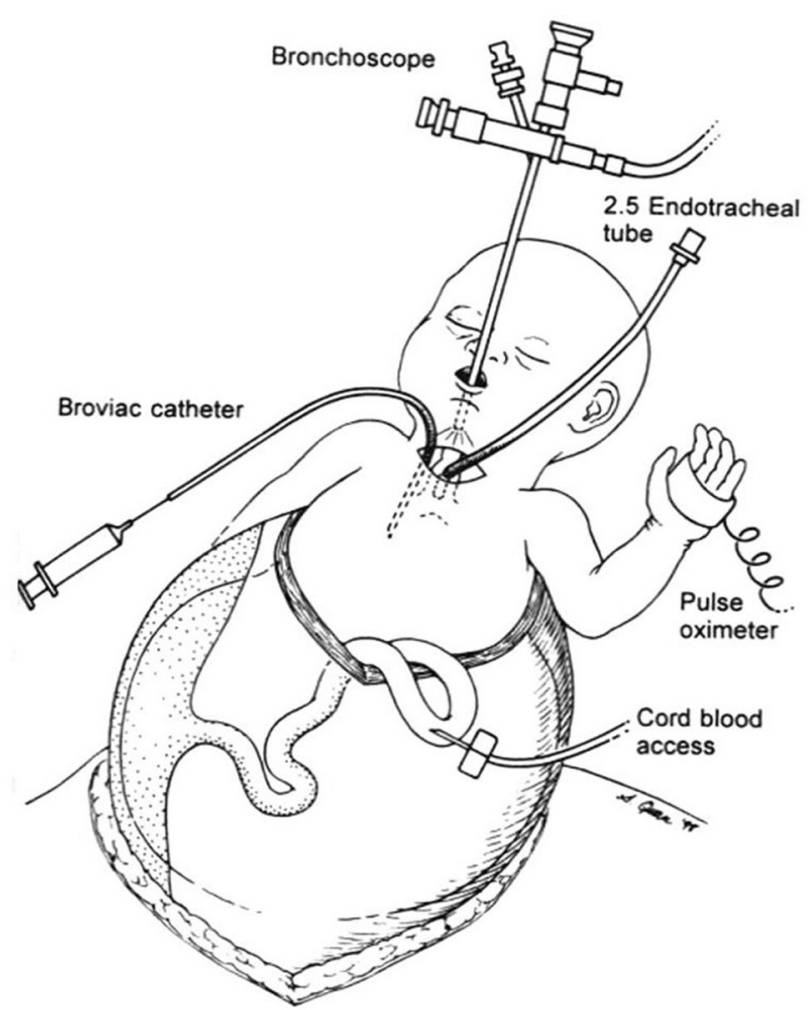

Figure 8 Schematic depiction of ex utero intrapartum treatment, with permission (39).

namely thoracoamniotic shunts, in hydropic fetuses with large lesions containing a dominant macrocyst (34). Thoracoamniotic shunts may also be indicated for hydropic fetuses with an associated ipsilateral pleural effusion (36). In these situations, steroids are often attempted first, with a percutaneous shunt placement reserved for non-responders.

Shunting procedures are performed under ultrasound guidance with minimal disruption to the uterus and amniotic sac using a $2.5 \mathrm{~mm}$ trocar assembly into the cavity of interest. The sharp trocar is then withdrawn into the introducer sleeve and replaced with the shunt catheter. Finally, the introducer sleeve is withdrawn, leaving the proximal end of the catheter in the amniotic space. The most commonly used shunts are $2.1 \mathrm{~mm}$ silastic catheters with pigtails that end at 90 degrees to each other, such as the KCH fetal bladder catheter (Rocket Medical) or the Harrison fetal bladder stent (Cook Urological). The double pigtail design helps to minimize shunt dislodgement and can theoretically remain in situ until birth.

Despite this being a minimally invasive procedure without the need for maternal anesthesia, there are still associated maternal-fetal risks. The CHOP group published a case series on thoracoamniotic shunt placement and reported peri-procedural complications including premature preterm rupture of membranes (PPROM), preterm labor, chorioamnionitis, shunt occlusion, and fetal dislodging of the shunt requiring a new shunt placement with the same risks. Another study followed post shunt candidates after birth and demonstrated postnatal rib deformities in $77 \%$ of the neonates. The deformities ranged from mild rib thinning to severe chest concavity (37).

\section{Fetal lung resection}

Until the introduction of steroids as first-line therapy for hydrops in the setting of microcystic disease, prenatal lung resection via open surgery was the mainstay procedure in the rare hydropic fetus before the third trimester. Less invasive alternatives, including various lasers and coagulators, have been tried with varying success in an attempt to effectively ablate fetal lung tumors (38). Unfortunately, many of these technologies tend to cause local edema first, thereby worsening the situation before improving physiology.

Open fetal lung resection was pioneered by Harrison and colleagues at UCSF. It has the potential for significant morbidity because it involves maternal laparotomy, maternal hysterectomy, and fetal thoracotomy incisions (Figure 8) (39). Full uterine relaxation is required in order to optimize uteroplacental circulation during fetal manipulation. The fetus should be free of other anomalies, and a karyotype is required to rule out a concomitant fatal aneuploidy. The mother should also be counseled of her personal risk and excluded from fetal surgical intervention if she does not meet stringent criteria.

Currently, fetal lung resection is reserved for previable and borderline viable hydropic fetuses with solid lesions (i.e., microcystic CPAMs and BPS) that are nonresponders to a trial of maternal steroids. Given the highrisk for complications, including maternal exsanguination and preterm labor, this endeavor requires a highly skilled, multidisciplinary team consisting of a cadre of specialists, each with a defined role within the operating room. It is therefore not surprising that fetal resection has only been successfully performed in a reproducible fashion at a handful of fetal surgery centers worldwide $(29,40)$. Preoperative preparation typically begins several hours before the procedure with the administration of tocolytic agents to minimize perioperative preterm labor. Prior to 
induction, mothers may receive a lumbar epidural catheter to minimize postoperative pain and uterine irritability. Deep general anesthesia with isoflurane or desflurane is used to decrease uterine tone, while simultaneously maintaining maternal blood pressure at preoperative levels thereby preserving maternal-fetal gas exchange at the placental interface. Common intraoperative maternal monitoring includes an invasive arterial line, continuous echocardiography and pulse oximetry, and an end-tidal carbon dioxide monitor. Aggressive fluid resuscitation with crystalloid is generally avoided because of the risk of postoperative pulmonary edema associated with tocolytic agents, particularly magnesium sulfate.

After a low transverse incision has been made on the maternal abdomen, the position of the placenta is mapped with ultrasound and marked on the surface of the uterus. The uterus is then opened using a specially designed, uterine stapler device containing lactomer staples. The stapler helps to create an $8-10 \mathrm{~cm}$ bloodless hysterotomy and maintains the integrity of the fragile chorion and amnion in setting of complete uterine relaxation. Once the uterus is opened, medications are given for fetal analgesia (e.g., fentanyl $10 \mathrm{mg} / \mathrm{kg}$ intramuscularly) and neuromuscular blockade (e.g., vecuronium $200 \mathrm{mg} / \mathrm{kg}$ intramuscularly). To maintain uterine distention, a catheter connected to a Level I-type rapid infuser is placed deep into the amniotic cavity for continuous infusion of warm lactated Ringer's solution at $400 \mathrm{~mL}$ per minute. During fetal manipulation, consideration must be made toward profound intraoperative fluid shifts. Therefore, the procedure requires fetal intravenous (IV) access followed by pretreatment with fluid (blood) and atropine for volume expansion and cardiac support. A standard TA stapling device is often utilized during the resection phase of the operation to remove the mass from the hilum. A meticulous hysterotomy closure is essential because the presence of amniotic fluid between the membranes and the myometrium is a powerful stimulus to preterm labor. At the time of uterine closure, a 6 gram bolus of magnesium sulfate followed by a continuous infusion at 2 grams per hour is initiated.

The overall mortality risk associated with open fetal surgery is approximately $50 \%$. Adzick and colleagues recently described 24 cases of open fetal surgery for lung lesion (30). There were 13 survivors with 11 fetal deaths. Among these deaths, one mother developed maternal mirror syndrome and required immediate delivery. Six babies died intra-operatively likely related to a massive cardiac decompression after removal of the large lesion (30).
After fetal surgery, there is risk of preterm premature rupture of membranes and preterm labor, both of which can add further morbidity to both mother and fetus. When the suitable delivery time has been agreed, the mother then has to undergo a cesarean section as her non-classical hysterotomy has not healed in a manner to withstand labor forces. There can also be deleterious consequences in light of the increased risk for placenta accreta, maternal and fetal morbidity, and mortality related to cesarean sections. There is an increased risk for intra-abdominal adhesions that have been known to create both technical surgical difficulties at the time of cesarean section and can lead to increased risk for bladder and bowel injuries.

\section{The EXIT procedure}

The EXIT procedure was perfected at UCSF as a perinatal operative maneuver just prior to delivery to ensure a smooth transition of the fetus to postnatal life (41). The role and indications for an EXIT procedure for lung masses remain somewhat controversial, but proponents argue that it provides an unparalleled, hemodynamically stable environment for the child, thereby maximizing the chance for survival in hydropic fetuses that have reached the stage of viability.

In an EXIT procedure, a maternal laparotomy and low transverse uterine segment hysterotomy are performed using the standard techniques of open fetal surgery. Deep maternal anesthesia is required to facilitate complete uterine relaxation and to maintain "placental bypass" to the fetus following a hysterotomy. The fetal head and torso are then exteriorized from the uterus, followed by orotracheal intubation and placement of a peripheral IV (Figure 9). In most cases, the lung mass is resected through a large thoracotomy while still on placental support (42).

The rationale for the EXIT-to-resection approach is based on the ability to provide immediate relief of severe mediastinal compression in order to allow for adequate room for the native lungs to function postnatally. EXITto-resection procedures can be performed with excellent outcomes (43). Alternatively, hydropic fetuses with smaller lesions could undergo a trial of ventilation with emergent neonatal lung resection performed in an adjacent operating room after delivery. Delayed mass resection following cannulation of the fetus for ECMO while on placental support has also been reported when more complex, tedious thoracic surgical procedures (e.g., carinal resection for an obstructing bronchogenic cyst) are required for definitive 


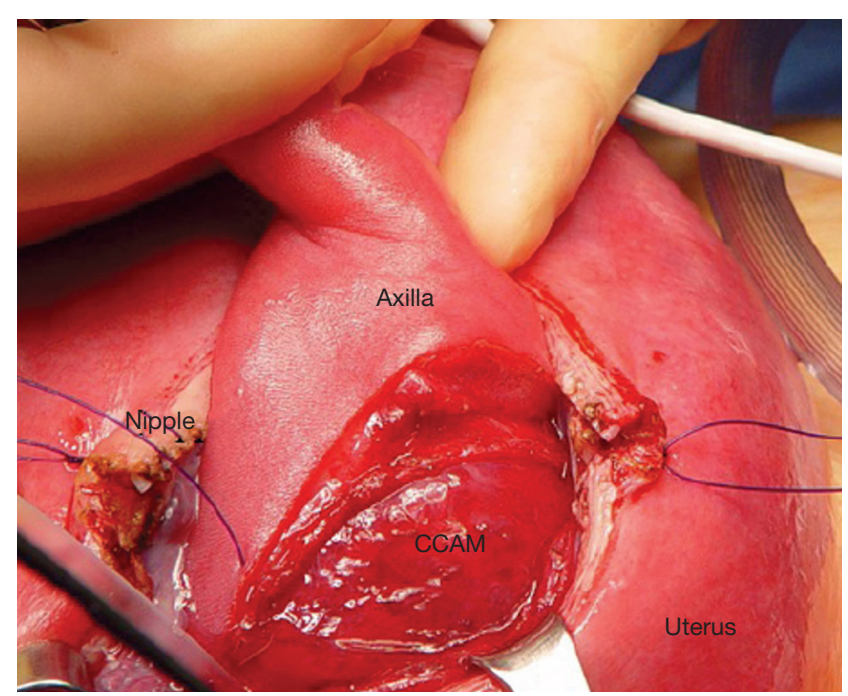

Figure 9 Fetal left thoracotomy and lobectomy for a congenital pulmonary airway malformation.

treatment (44).

\section{Postnatal management of lung lesions}

Newborns with respiratory symptoms represent $10 \%$ of prenatally diagnosed lung malformations and can be reliably predicted based on elevated CVRs (20). In the presence of respiratory distress, plain films of the chest are the best initial study to determine the degree of mediastinal shift and to rule out an associated pneumothorax. Echocardiograms should be performed to assess for right heart function and to look for congenital heart defects. Thoracotomy and lobectomy in symptomatic neonates are the standard of care. A preoperative computed tomography (CT) scan is ideal in most cases since a systemic feeding vessel may be present, regardless of negative findings from prenatal ultrasound (25). Rarely, a thoracotomy may be required on an emergent basis, particularly in CLE lesions, due to rapid and progressive air trapping exacerbated by positive pressure ventilation. The need for perioperative ECMO is rare but can be a life-saving option to support these children (1).

Asymptomatic patients typically have CVRs consistently less than 0.9 and make up approximately $90 \%$ of children with a prenatally diagnosed lung malformation (5). Newborns can usually be discharged from the hospital in accordance with established well-baby protocols. However, prior to discharge, chest radiographs are often ordered to establish a baseline for subsequent imaging. However, these studies may appear as normal since the sensitivity for detecting a pulmonary mass is between $50-80 \%(17,45)$. A congenital lung mass should never be ruled out based solely on plain films.

Follow-up with a pediatric surgeon at between 4-12 weeks of age is recommended in all asymptomatic cases. The gold standard diagnostic test to determine the presence or absence of a lung lesion is a chest CT scan with intravenous contrast. Sedation/general anesthesia during this study is sometimes required for older infants who cannot be calmed by swaddling.

The role and timing of surgery in asymptomatic lung lesions remains controversial, particularly of the United States $(46,47)$. The rationale for preemptive resection of CPAM and BPS lesions is based on the desire to avoid predictable and well-known complication of pneumonia refractory to antibiotics. Intralobar BPS and CPAMs are particularly susceptible to pneumonias and pulmonary abscesses, presumably due to impaired mucociliary clearance of pathogens. However, the true pneumonia risk has not been well defined and ranges from $5 \%$ to $86 \%(47-49)$. Malignant degeneration of CPAMs has been described (50), but the overall risk is probably extremely low for prenatally diagnosed lesions ( $<1 \%)$. More importantly, cases of cystic pleuropulmonary blastoma (PPB), a malignant lung tumor seen in infants and associated with the DICER1 mutation in many cases, have also been observed in lesions that were thought to be macrocystic CPAMs based on cross-sectional imaging $(51,52)$. It is important to note that PPB cases tend to be symptomatic, are usually not detected antenatally, and do not have a systemic blood supply.

Another area of interest in the postnatal care of lung malformations is the role of non-operative management as an evolving management strategy in selected situations. Some surgeons in Europe, the United Kingdom, and elsewhere have argued for the observation of asymptomatic lung malformations, particularly those that were prenatally diagnosed and appear to be small CPAMs, CLEs, or extralobar BPS lesions because their natural history is believed to be more benign $(47,53)$. Proponents on nonoperative management would also argue that surgical management is not always well tolerated and exposes children to potential major postoperative morbidity $(1,44)$. In one review from the United Kingdom, children who subsequently developed symptoms requiring lung surgery was uncommon at a median follow up of five years (49). The costs and radiation risks associated with serial imaging are the main drawbacks of non-operative management in 
the long term. Should one of these lesions become infected, they tend to be not very responsive to antibiotics and may mandate prolonged hospitalization. The pleural scarring that can occur following a previously infected lesion can also make delayed resection of lung malformations more dangerous and difficult (54).

Under the care of an experienced pediatric surgeon, the operative morbidity of an elective lung resection is low (55). The widespread adoption of minimally invasive lung resection has been witnessed over the past decade (56), and the majority of all elective lung resections are now performed using thoracoscopic techniques. Outcomes after thoracoscopic lobectomy result in excellent cosmesis. Muscle-sparing thoracotomy incisions represent a viable alternative and are associated with relatively low long-term musculoskeletal morbidity (13). Formal anatomic lobectomy is preferred to partial lobectomies (e.g., segmentectomies, wedge resections), which have an increased potential of inadvertently leaving behind residual disease. The median hospital length of stay, regardless of operative approach, is approximately three days (56). The optimal timing of elective lung surgery remains undefined (1), but some North American and European surgeons have advocated lung resections by six months of age before the onset of pneumonia and to maximize the opportunity for compensatory lung growth $(13,57,58)$.

\section{Conclusions}

Because of the relative rarity of CPAMs, BPS, and other congenital lung malformations, they continue to be misunderstood entities by some pediatric providers. However, as ultrasound imaging continues to improve, the diagnosis and management of these masses during the prenatal period will only become more frequent, and our knowledge will increase. Regardless, it is vital that these lesions are appropriately managed because of the longterm prognosis should be excellent in most cases. Based on measurement tools such as the CVR, we are now gaining a better understanding of their growth patterns and have developed useful sonographic parameters to predict fetal well-being. Serial growth ultrasounds should be performed to evaluate the mass, to assess the fetus for other anomalies and to plan for delivery and future treatment. Fetal MRI and other diagnostic testing can sometimes be helpful in providing additional prognostic information. At this current time, invasive fetal intervention is reserved for hydropic patients who have failed steroid therapy. We have learned that prenatal diagnosis of the type of malformation is not particularly helpful in terms of gauging risk for hydrops, respiratory morbidity, and long-term outcomes.

A multi-disciplinary team should play a vital role in ensuring that the mother and fetus receive current and recommended treatment and are managed antenatally, intrapartum, and postnatally with utmost care. Even in asymptomatic babies, or those infants with ultrasounds suggestive of a vanishing lesion, they should still undergo investigation with a postnatal CT and evaluation with a pediatric surgeon because of the risk of long-term sequelae.

\section{Acknowledgments}

Funding: None.

\section{Footnote}

Provenance and Peer Review: This article was commissioned by the Guest Editors (Eric B. Jelin and George B. Mychaliska) for the series "Fetal Surgery" published in Translational Pediatrics. The article has undergone external peer review.

Reporting Checklist: The author has completed the Narrative Review reporting checklist. Available at http://dx.doi. org/10.21037/tp-20-133

Conflicts of Interest: The author has completed the ICMJE uniform disclosure form (available at http://dx.doi. org/10.21037/tp-20-133). The series "Fetal Surgery" was commissioned by the editorial office without any funding or sponsorship. The author has no other conflicts of interest to declare.

Ethical Statement: The author is accountable for all aspects of the work in ensuring that questions related to the accuracy or integrity of any part of the work are appropriately investigated and resolved.

Open Access Statement: This is an Open Access article distributed in accordance with the Creative Commons Attribution-NonCommercial-NoDerivs 4.0 International License (CC BY-NC-ND 4.0), which permits the noncommercial replication and distribution of the article with the strict proviso that no changes or edits are made and the original work is properly cited (including links to both the formal publication through the relevant DOI and the license). See: https://creativecommons.org/licenses/by-nc-nd/4.0/. 


\section{References}

1. Kunisaki SM, Saito JM, Fallat ME, et al. Development of a multi-institutional registry for children with operative congenital lung malformations. J Pediatr Surg 2020;55:1313-8.

2. Lima JS, Camargos PA, Aguiar RA, et al. Pre and perinatal aspects of congenital cystic adenomatoid malformation of the lung. J Matern Fetal Neonatal Med 2014;27:228-32.

3. Lau CT, Kan A, Shek N, et al. Is congenital pulmonary airway malformation really a rare disease? Result of a prospective registry with universal antenatal screening program. Pediatr Surg Int 2017;33:105-8.

4. Stocker JT, Madewell JE, Drake RM. Congenital cystic adenomatoid malformation of the lung. Classification and morphologic spectrum. Hum Pathol 1977;8:155-71.

5. Ehrenberg-Buchner S, Stapf AM, Berman DR, et al. Fetal lung lesions: can we start to breathe easier? Am J Obstet Gynecol 2013;208:151.e1-7.

6. Kunisaki SM, Leys CM. Surgical Pulmonary and Pleural Diseases in Children: Lung Malformations, Empyema, and Spontaneous Pneumothorax. Adv Pediatr 2020;67:145-69.

7. Stocker JT. Cystic lung disease in infants and children. Fetal Pediatr Pathol 2009;28:155-84.

8. Adzick NS, Harrison MR, Glick PL, et al. Fetal cystic adenomatoid malformation: prenatal diagnosis and natural history. J Pediatr Surg 1985;20:483-8.

9. Langston C. New concepts in the pathology of congenital lung malformations. Semin Pediatr Surg 2003;12:17-37.

10. Kunisaki SM, Fauza DO, Nemes LP, et al. Bronchial atresia: the hidden pathology within a spectrum of prenatally diagnosed lung masses. J Pediatr Surg 2006;41:61-5; discussion 65.

11. Morotti RA, Gutierrez MC, Askin F, et al. Expression of thyroid transcription factor- 1 in congenital cystic adenomatoid malformation of the lung. Pediatr Dev Pathol 2000;3:455-61.

12. Cass DL, Quinn TM, Yang EY, et al. Increased cell proliferation and decreased apoptosis characterize congenital cystic adenomatoid malformation of the lung. J Pediatr Surg 1998;33:1043-6; discussion 1047.

13. Tsai AY, Liechty KW, Hedrick HL, et al. Outcomes after postnatal resection of prenatally diagnosed asymptomatic cystic lung lesions. J Pediatr Surg 2008;43:513-7.

14. Ruano R, Benachi A, Aubry MC, et al. Prenatal diagnosis of pulmonary sequestration using three-dimensional power Doppler ultrasound. Ultrasound Obstet Gynecol 2005;25:128-33.
15. Macardle CA, Ehrenberg-Buchner S, Smith EA, et al. Surveillance of fetal lung lesions using the congenital pulmonary airway malformation volume ratio: natural history and outcomes. Prenat Diagn 2016;36:282-9.

16. Fievet L, D'Journo XB, Guys JM, et al. Bronchogenic cyst: best time for surgery? Ann Thorac Surg 2012;94:1695-9.

17. Kunisaki SM, Saito JM, Fallat ME, et al. Current operative management of congenital lobar emphysema in children: A report from the Midwest Pediatric Surgery Consortium. J Pediatr Surg 2019;54:1138-42.

18. Tapper D, Schuster S, McBride J, et al. Polyalveolar lobe: anatomic and physiologic parameters and their relationship to congenital lobar emphysema. J Pediatr Surg 1980;15:931-7.

19. Mei-Zahav M, Konen O, Manson D, et al. Is congenital lobar emphysema a surgical disease? J Pediatr Surg 2006;41:1058-61.

20. Kunisaki SM, Saito JM, Fallat ME, et al. Fetal Risk Stratification and Outcomes in Children with Prenatally Diagnosed Lung Malformations: Results from a MultiInstitutional Research Collaborative. Ann Surg 2020. [Epub ahead of print].

21. Macardle CA, Kunisaki SM. Management of perinatal lung malformations. Minerva Ginecol 2015;67:81-94.

22. Ruchonnet-Metrailler I, Leroy-Terquem E, Stirnemann J, et al. Neonatal outcomes of prenatally diagnosed congenital pulmonary malformations. Pediatrics 2014;133:e1285-91.

23. Girsen AI, Hintz SR, Sammour R, et al. Prediction of neonatal respiratory distress in pregnancies complicated by fetal lung masses. Prenat Diagn 2017;37:266-72.

24. Crombleholme TM, Coleman B, Hedrick H, et al. Cystic adenomatoid malformation volume ratio predicts outcome in prenatally diagnosed cystic adenomatoid malformation of the lung. J Pediatr Surg 2002;37:331-8.

25. Mon RA, Johnson KN, Ladino-Torres M, et al. Diagnostic accuracy of imaging studies in congenital lung malformations. Arch Dis Child Fetal Neonatal Ed 2019;104:F372-7.

26. Riley JS, Urwin JW, Oliver ER, et al. Prenatal growth characteristics and pre/postnatal management of bronchopulmonary sequestrations. J Pediatr Surg 2018;53:265-9.

27. Meizner I, Rosenak D. The vanishing fetal intrathoracic mass: consider an obstructing mucous plug. Ultrasound Obstet Gynecol 1995;5:275-7.

28. Kunisaki SM, Ehrenberg-Buchner S, Dillman JR, et al. Vanishing fetal lung malformations: Prenatal sonographic 
characteristics and postnatal outcomes. J Pediatr Surg 2015;50:978-82.

29. Cass DL, Olutoye OO, Cassady CI, et al. Prenatal diagnosis and outcome of fetal lung masses. J Pediatr Surg 2011;46:292-8.

30. Adzick NS. Management of fetal lung lesions. Clin Perinatol 2009;36:363-76, x.

31. Cass DL, Olutoye OO, Ayres NA, et al. Defining hydrops and indications for open fetal surgery for fetuses with lung masses and vascular tumors. J Pediatr Surg 2012;47:40-5.

32. Tsao K, Hawgood S, Vu L, et al. Resolution of hydrops fetalis in congenital cystic adenomatoid malformation after prenatal steroid therapy. J Pediatr Surg 2003;38:508-10.

33. Loh KC, Jelin E, Hirose S, et al. Microcystic congenital pulmonary airway malformation with hydrops fetalis: steroids vs open fetal resection. J Pediatr Surg 2012;47:36-9.

34. Peranteau WH, Wilson RD, Liechty KW, et al. Effect of maternal betamethasone administration on prenatal congenital cystic adenomatoid malformation growth and fetal survival. Fetal Diagn Ther 2007;22:365-71.

35. Morris LM, Lim FY, Livingston JC, et al. High-risk fetal congenital pulmonary airway malformations have a variable response to steroids. J Pediatr Surg 2009;44:60-5.

36. Adzick NS, Harrison MR, Crombleholme TM, et al. Fetal lung lesions: management and outcome. Am J Obstet Gynecol 1998;179:884-9.

37. Merchant AM, Peranteau W, Wilson RD, et al. Postnatal chest wall deformities after fetal thoracoamniotic shunting for congenital cystic adenomatoid malformation. Fetal Diagn Ther 2007;22:435-9.

38. Lee FL, Said N, Grikscheit TC, et al. Treatment of congenital pulmonary airway malformation induced hydrops fetalis via percutaneous sclerotherapy. Fetal Diagn Ther 2012;31:264-8.

39. Kunisaki SM, Jennings RW. Fetal surgery. J Intensive Care Med 2008;23:33-51.

40. Grethel EJ, Wagner AJ, Clifton MS, et al. Fetal intervention for mass lesions and hydrops improves outcome: a 15-year experience. J Pediatr Surg 2007;42:117-23.

41. Mychaliska GB, Bealer JF, Graf JL, et al. Operating on placental support: the ex utero intrapartum treatment procedure. J Pediatr Surg 1997;32:227-30; discussion 230-1.

42. Hedrick HL, Flake AW, Crombleholme TM, et al. The ex utero intrapartum therapy procedure for high-risk fetal lung lesions. J Pediatr Surg 2005;40:1038-43; discussion
1044.

43. Cass DL, Olutoye OO, Cassady CI, et al. EXIT-toresection for fetuses with large lung masses and persistent mediastinal compression near birth. J Pediatr Surg 2013;48:138-44.

44. Kunisaki SM, Fauza DO, Barnewolt CE, et al. Ex utero intrapartum treatment with placement on extracorporeal membrane oxygenation for fetal thoracic masses. J Pediatr Surg 2007;42:420-5.

45. Calvert JK, Lakhoo K. Antenatally suspected congenital cystic adenomatoid malformation of the lung: postnatal investigation and timing of surgery. J Pediatr Surg 2007;42:411-4.

46. Aziz D, Langer JC, Tuuha SE, et al. Perinatally diagnosed asymptomatic congenital cystic adenomatoid malformation: to resect or not? J Pediatr Surg 2004;39:329-34; discussion 334.

47. Criss CN, Musili N, Matusko N, et al. Asymptomatic congenital lung malformations: Is nonoperative management a viable alternative? J Pediatr Surg 2018;53:1092-7.

48. Wong A, Vieten D, Singh S, et al. Long-term outcome of asymptomatic patients with congenital cystic adenomatoid malformation. Pediatr Surg Int 2009;25:479-85.

49. Ng C, Stanwell J, Burge DM, et al. Conservative management of antenatally diagnosed cystic lung malformations. Arch Dis Child 2014;99:432-7.

50. Casagrande A, Pederiva F. Association between Congenital Lung Malformations and Lung Tumors in Children and Adults: A Systematic Review. J Thorac Oncol 2016;11:1837-45.

51. Miniati DN, Chintagumpala M, Langston C, et al. Prenatal presentation and outcome of children with pleuropulmonary blastoma. J Pediatr Surg 2006;41:66-71.

52. Nasr A, Himidan S, Pastor AC, et al. Is congenital cystic adenomatoid malformation a premalignant lesion for pleuropulmonary blastoma? J Pediatr Surg 2010;45:1086-9.

53. Lo AY, Jones S. Lack of consensus among Canadian pediatric surgeons regarding the management of congenital cystic adenomatoid malformation of the lung. J Pediatr Surg 2008;43:797-9.

54. Durell J, Thakkar H, Gould S, et al. Pathology of asymptomatic, prenatally diagnosed cystic lung malformations. J Pediatr Surg 2016;51:231-5.

55. Rothenberg SS, Kuenzler KA, Middlesworth W, et al. Thoracoscopic lobectomy in infants less than $10 \mathrm{~kg}$ with prenatally diagnosed cystic lung disease. J Laparoendosc 
Adv Surg Tech A 2011;21:181-4.

56. Kunisaki SM, Powelson IA, Haydar B, et al. Thoracoscopic vs open lobectomy in infants and young children with congenital lung malformations. J Am Coll Surg 2014;218:261-70.

57. Conforti A, Aloi I, Trucchi A, et al. Asymptomatic congenital cystic adenomatoid malformation of the

Cite this article as: Kunisaki SM. Narrative review of congenital lung lesions. Transl Pediatr 2021;10(5):1418-1431. doi: $10.21037 / \mathrm{tp}-20-133$ lung: is it time to operate? J Thorac Cardiovasc Surg 2009; 138:826-30.

58. Jelin EB, O'Hare EM, Jancelewicz T, et al. Optimal timing for elective resection of asymptomatic congenital pulmonary airway malformations. J Pediatr Surg 2018;53:1001-5. 